\title{
Lamellar ichthyosis-like eruption associated with ponatinib
}

\author{
Özge Mine Örenay ${ }^{1 凶}$, Funda Tamer ${ }^{1}$, Evren Sarıfakıoğlu ${ }^{1}$, Umran Yıldırım² \\ Received: 22 June 2016 | Returned for modification: 1 August 2016 | Accepted: 12 August 2016
}

\section{To the Editor:}

A 51-year-old woman presented with a 5-month history of slowly spreading erythematous rash and complaint of pruritus. Dermatological examination revealed erythematous coalescing patches with dry scales on the trunk and kserosis predominantly on the extremities (Figs. 1a, b).

The patient was diagnosed with Philadelphia chromosomepositive acute lymphoblastic leukemia (ALL) in 2012. Initially, she was treated with tyrosine kinase inhibitors, including imatinib and nilotinib. However, complete remission was not achieved. Therefore, she was started on ponatinib, $45 \mathrm{mg}$ daily. An erythematous rash developed 1 month after ponatinib treatment was started. Skin biopsy from the abdominal lesion showed laminated orthokeratosis, a normal granular layer, and a thickened granular layer in some areas. Moreover, there were effacement of the rete ridges and sparse perivascular lymphocytic infiltration around superficial dilated vessels (Fig. 2). Based on clinical and histopathological features, the patient was diagnosed with lamellar ichthyosis-like eruption. Complete clearance of the eruption was achieved after 10 days of treatment with topical clobetasol propionate and urea $2 \%$ twice daily. However, kserosis recurred on the extremities within 1 month. Despite the cutaneous side effect, the patient was able to continue chemotherapy. ALL did not respond to 9 months of therapy with ponatinib.

Acquired ichthyosis can be associated with medications, malignancies, and autoimmune, infectious, neurological, nutritional, endocrine, and metabolic diseases $(1,2)$. Histologically, acquired ichthyosis is usually characterized by compact or laminated orthohyperkeratosis, a reduced or absent granular layer, and the absence of inflammatory infiltrate in the dermis $(1,2)$. However, mild perivascular lymphohistiocytic infiltrate in the dermis has also been reported (1).

In our case, ichthyosis may be due to malignancy or medication use. However, the patient had ALL for 3 years and she did not have any cutaneous lesions during imatinib or nilotinib therapy. Furthermore, the skin lesions occurred within 1 month of ponatinib therapy. Therefore, we associated the ichthyosis-like eruption with ponatinib rather than malignancy.

Ponatinib is a third-generation tyrosine kinase inhibitor that has been used in chronic myelogenous leukemia and ALL treatment in recent years. Nonspecific rash and kserosis have been reported with ponatinib and other tyrosine kinase inhibitors (3). Recently, new cases of cutaneous eruptions induced by ponatinib have been reported, which include two cases of pythriasis rubra pilaris-like eruption, a folliculocentric form, a seborrhoeic form, an ichthyosiform eruption, and neutrophilic panniculitis (3-5). The mechanism of the cutaneous eruptions has not been clearly defined. However, it has been considered that signal inhibition of kinases and dysregulation of the inflammatory pathways may lead to altered immune regulation and abnormal epidermal growth $(3,6)$.

In this case report, we present a new cutaneous side effect of ponatinib "lamellar ichthyosis." The patients should be informed about possible cutaneous side effects and appropriate skin care to avoid unnecessary drug cessation. The recognition of the cutaneous toxicities of new anti-cancer therapies will improve the quality of life in cancer patients and perhaps the discovery of new drugs with a better side-effect profile.

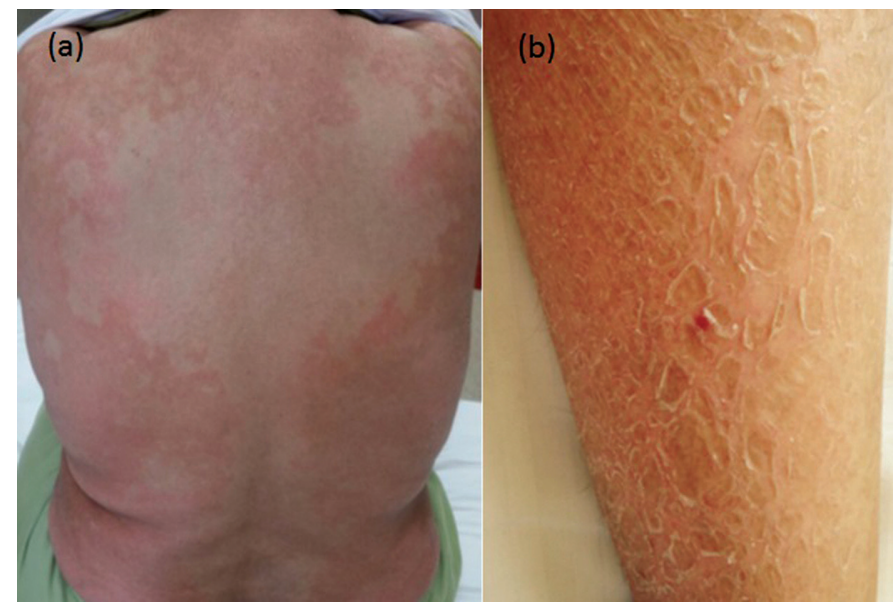

Figure 1 | (a) Erythematous coalescing patches with dry scales on the back, (b) Kserosis on the right leg.

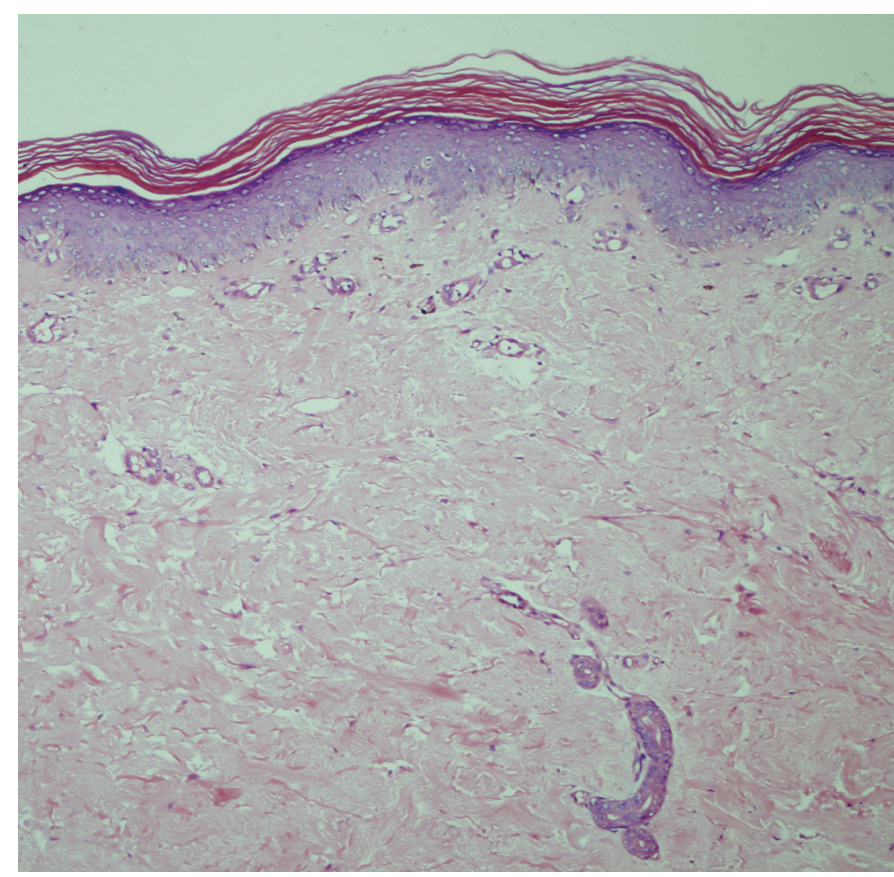

Figure 2 | Laminated orthokeratosis, normal granular layer, and thickened granular layer in some areas, some effacement of the rete ridges, and sparse perivascular lymphocytic infiltration around superficial dilated vessels (H\&E, $\times 100)$ 


\section{References}

1. Patel N, Spencer LA, English JC, Zirwas MJ. Acquired ichthyosis. J Am Acad Dermatol. 2006;55:647-56.

2. Word AP, Cayce R, Pandya AG. Beware of underlying malignancy: acquired ichthyosis. Am J Med. 2014;127:202-4.

3. Alloo A, Sheu J, Butrynski JE, DeAngelo DJ, George S, Murphy GF, et al. Ponatinibinduced pityriasiform, folliculocentric and ichthyosiform cutaneous toxicities. $\mathrm{Br}$ J Dermatol. 2015;173:574-7.
4. Jack A, Mauro MJ, Ehst BD. Pityriasis rubra pilaris-like eruption associated with the multikinase inhibitor ponatinib. J Am Acad Dermatol. 2013;69:249-50.

5. Zhang M, Hassan KM, Musiek A, Rosman IS. Ponatinib-induced neutrophilic panniculitis. J Cutan Pathol. 2014;41:597-601.

6. Patel AB, Solomon AR, Mauro MJ, Ehst BD. Unique cutaneous reaction to secondand third-generation tyrosine kinase inhibitors for chronic myeloid leukemia. Dermatology. 2016;232:122-5. 